\title{
بكوث التصميم
}

\section{التحوّلات في عملية الاتصال الجماهيري باستخدام الشبكة الدولية للمعلومات (الاترنت) في ظل التكنولوجيا الحديثة}

\section{Using the Transformations in The Process of Mass Communication International Network of Information (Internet)}

انتصار رسمي موسى

\section{Intisar Rasmi Mousa}

$$
\text { ملخص البحث }
$$

تتلخص فكرة البحث الموسوم "التحولات في عملية الاتصال الجماهيري باستخدام الشبكة الدولية

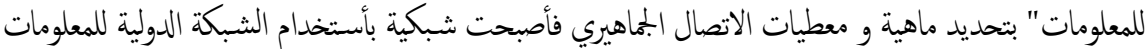

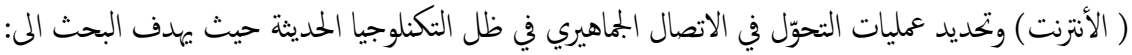

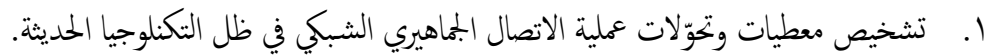

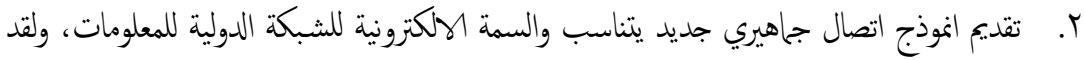

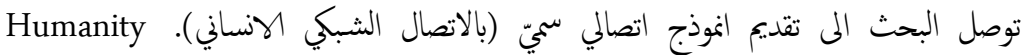
Communication Net

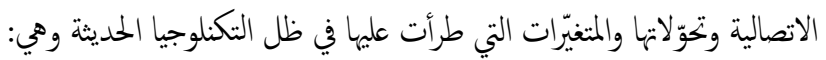

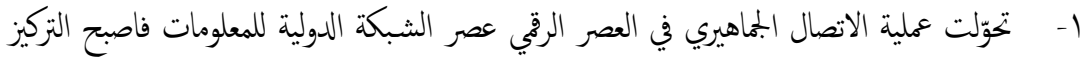

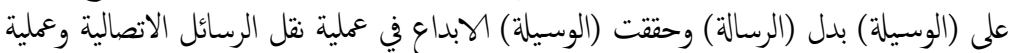

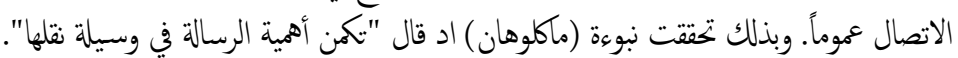

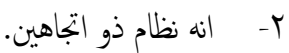

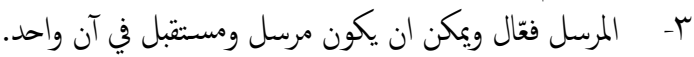

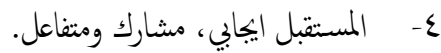
0- أصبحت الوسيلة الاتصالية- الشبكية وسيلة (مركّة) ومتعددة الوسائط .

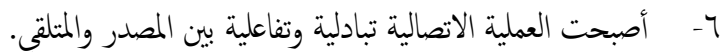

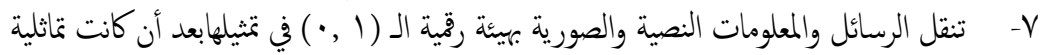

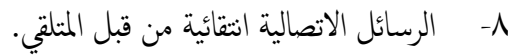
9- - بتميز الاتصال الرقمي عبر الانترنت (بالتفاعلية).

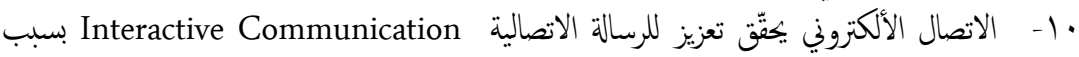

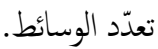
1 - البيئة الاتصالية الحديثة نظيفة وآمنة حيث تضعف عوامل التشويش. 


$$
\text { T ا- بتميز الاتصال الجماهيري الحديث بثرّاء معلوماتي واسع ومتداخل. }
$$

rا با- اصبحت عملية الاتصال (اتصال محوسب) computer-(Com-com) communication

\begin{abstract}
Summarized the idea of research is marked by "changes in the process of mass communication by using the international network of information" by specifying what data networking and mass communication is the transformation processes in the mass communication network where research aims to:

1. Diagnostic data and transformations in the process of mass communication network.

r. Provide a contact form commensurate with the characteristic mass of the International Network of electronic information, and research found to provide a communicative model called the (human contact network). In short (HCN) Humanity Communication Net also reached conclusions concerning the search process and communicative transformations and changes that have taken place by (the Internet).

1 - Turned the process of public communication in the digital age, the era of the international network of information, bringing a focus on the (the means) instead of (the message) and achieved (the means) creativity in the process of transferring messages connectivity and communication process in general. And so true prophecy (McLuhan), where he said,"the importance of the message lays in a way it transfer."

$r$ - It is a system with two-way.

$r$ - The sender's effective and can be a receiver and sender at the same time.

$\varepsilon$ - The future is positive and interactive participant.

- - The means of communication, networking means (vehicle) and multi-media.

7 - The process of communication is reciprocal between the source and the receiver.

$V$ - Transfer the messages and data in digital form using $(\cdot, l)$ in the representation.

$\wedge$ - Selective communication of messages by the receiver.

$q$ - Digital communications over the Internet is characterized by (interactive).

1. - Electronic communication to achieve the promotion of the message because of communication Interactive Communication Multimedia.
\end{abstract}


11 - The environment clean and safe communication as confusion factors weaken.

ir - Public communication is characterized by enrich of the in formations are wide and overlapping.

ir - Contact become a (contact computerized), Com-com computer communication.

ان التطورات السريعة التي شهدتها تكنلوجيا الاتصال والمستحدثات التي عززتها التقنيات الرقية

والتكنلوجيا الحديثة، بدأت تقودنا نحو ترتيب جديد للمنظومة الاتصالية، حيث تحولت العملية الاتصالية التقليدية واصبحت عملية انتقال المعاني تنطوي على عمليات تفاعل اتصالي من خلال سمة التفاعلية والتي وفرتها الشبكة تلميكة

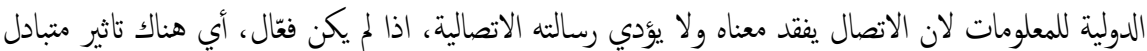

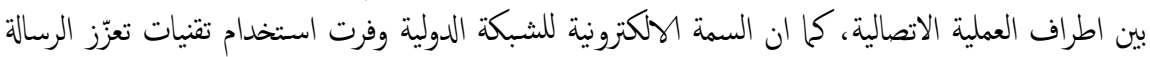

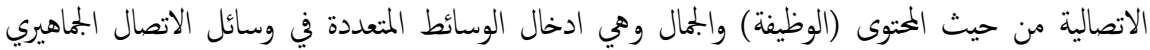

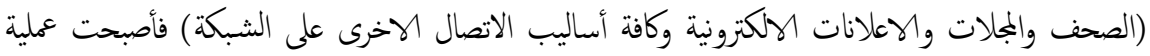

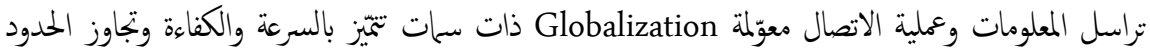

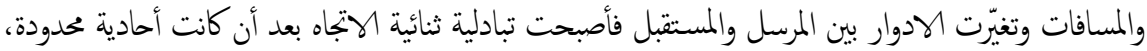

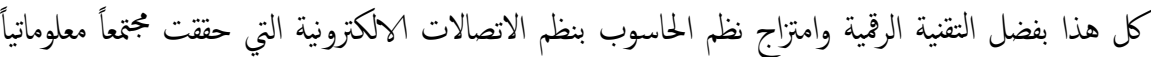

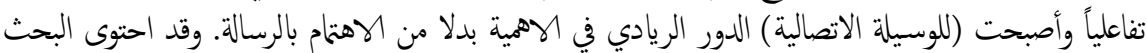
الحالي على محاور الدراسة وهي:

محور القاء الضوء على مفهوم الاتصال الجماهيري وماهيته باستخدام الشبكة الدولية للمعلومات ثم ما هي التحولات التي طرأت على عملية الاتصال التقليدية. ثم التعريف بعملية التغيير والتحول في عملية الاتصال

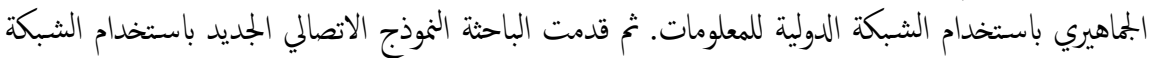

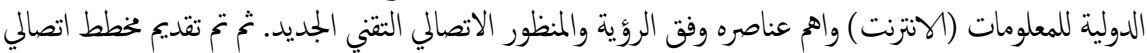

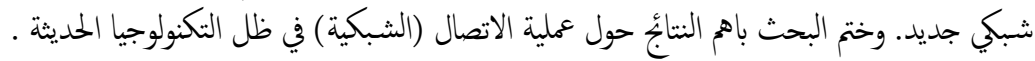

$$
\text { أولا": منهجية البحث }
$$

طرأت تحولات جذرية في العالم بسبب التغّرات التي طرأت على وسائل الاتصال والمعلومات ونتيجة للتغيرات التكنولوجية وانثثاق افكار جديدة عن الجوانب الانسانية للاتصال فقد هيأت وسائل الاتصال الحديثة

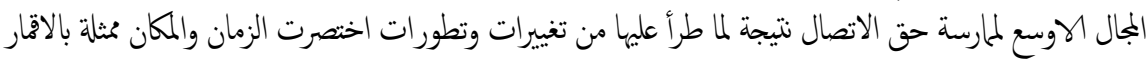

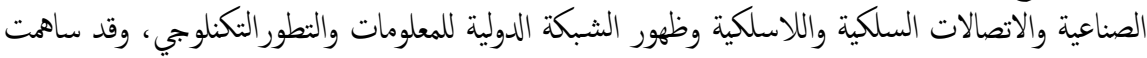




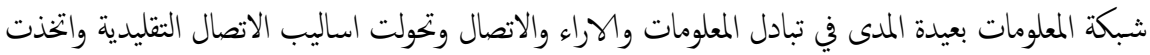

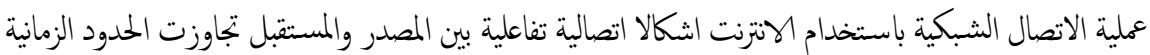

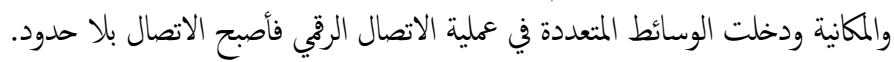

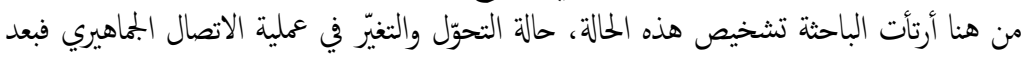

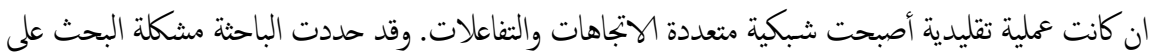
وفق التساؤل الاتي: (ما هي معطيات الاتصال الجماهيري الشبكي الحديث وما هي عمليات التحوّل في الاتصال الجماهيري في ظل المبل الشبكة الدولية للمعلومات والتطورات التكنلوجية الحديثة).

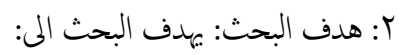

ץ-1 إ: تشخيص معطيات وتحوّلات عملية الاتصال الجماهيري الشبكي باستخدام الشبكة الدولية للمعلومات

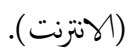

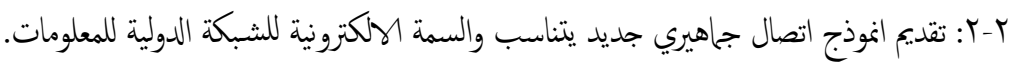

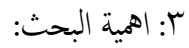

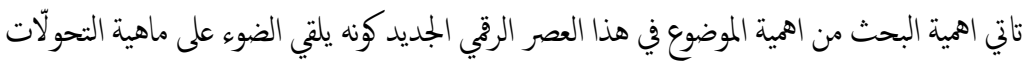

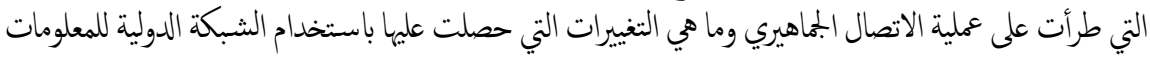
(الانترنت ) في ظل التطورات النكنلوجية الحديثة.

يتمثل بمتع البحث في دراسة عملية الاتصال وتحولاتها من خلال الشبكة الدولية للمعلومات.

$$
\text { ع: مجتع البحث: }
$$

$$
\text { 0: حدود البحث: }
$$

الموضوعية: دراسة عملية الاتصال الجماهيري وتحولاتهّا.

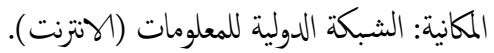

الزمانية: يتناول البحث رصد عملية الاتصال الـ process ولا يحتاج المى تحديد فتزة زمنية لان البحث يتناول رصد الظاهرة.

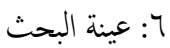

لا يجتاج البحث الى أخذ عينة لأنه يتناول دراسة "ظاهرة وهي عملية رصد وتحليل عملية الاتصال

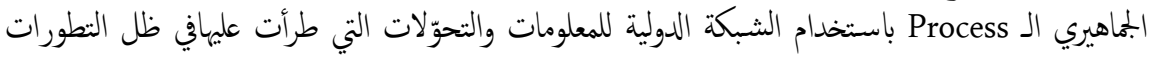
التكنلوجية الحديثة.

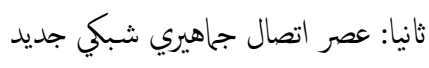

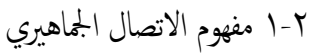

يعّرف الكثيرون الاتصال الجماهيري بأنه: نوع خاص من الاتصال ينطوي على اشتراطات مئميّة في الأداء

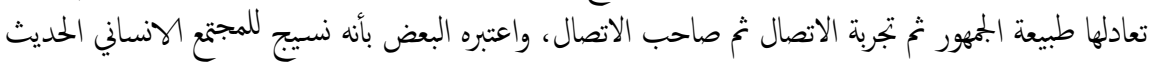


الذي تميّه قوة التكنولوجيا التي تتمثل في الانتاج الضخم والميكنة وتقدم وسائل الاتصالات وكلما تدفق الاعلام بين

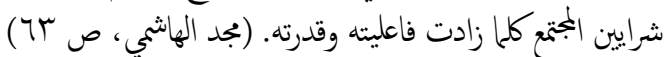

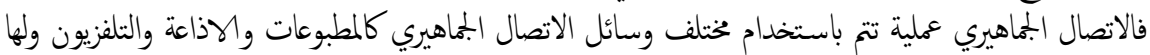

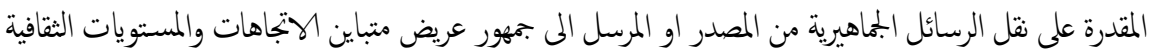

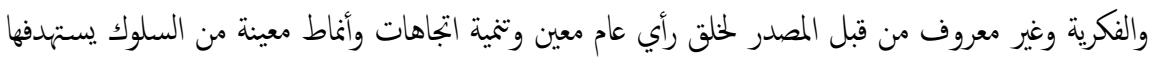

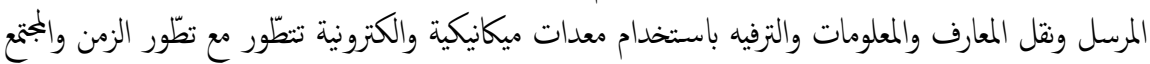
والتكنولوجيا. والاتصال الجماهيري يقدم رسائل بشكل منظم ومدروس تصدر عن مؤسسات للاتصال الجماهيري كالمؤسسات

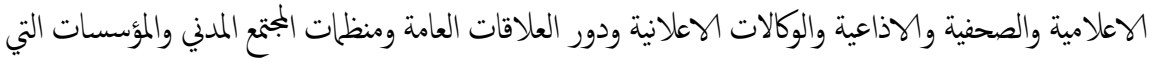

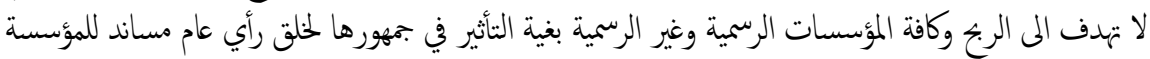
المعنة. لقد أصبح الاتصال الجماهيري اتصالاً كونياً بلا حدود تفاعلياً متعدد الوسائط، ولقد صدقت رؤية ماكلوهان "ان العالم سيصبح قرية صغيرة" بل نقول "ان العالم أصبح شانشة صغيرة".

r-T الاتصال الجماهيري في ظل الشبكة الدولية للمعلومات (الاترنت) والتكنلوجيا الحديثة

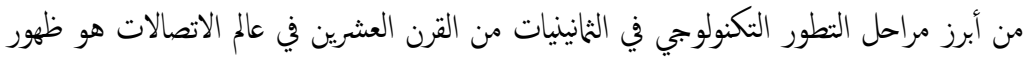

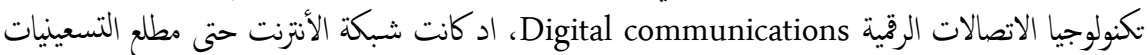

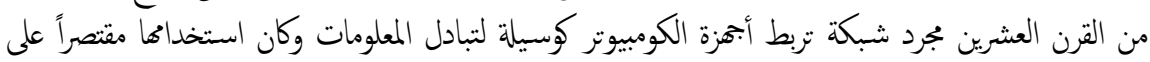

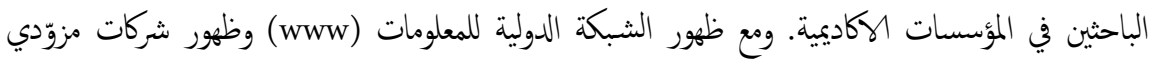

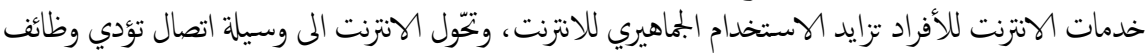

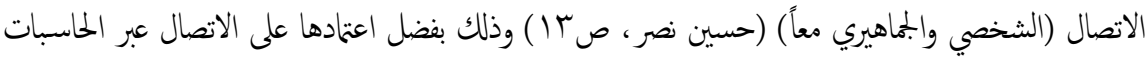

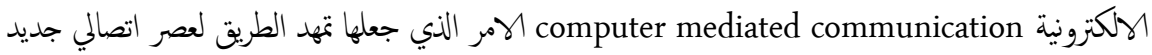

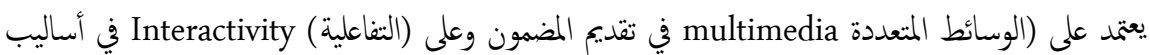

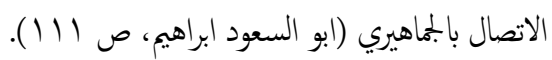

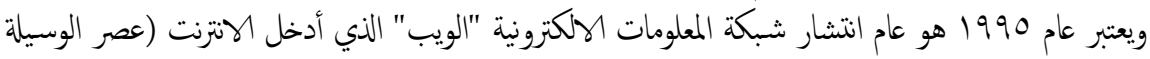

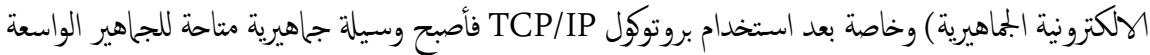

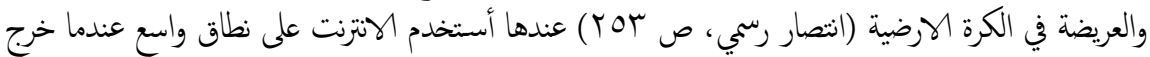

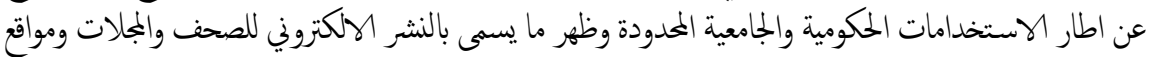

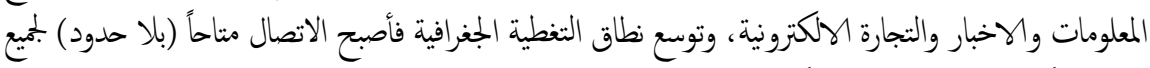

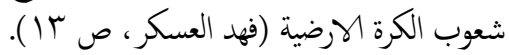


ولقد تزايدت أهمية الانترنت في الآونة الأخيرة كوسيلة اتصال جاهيرية حتى عدها البعض وسيلة

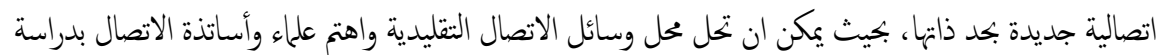

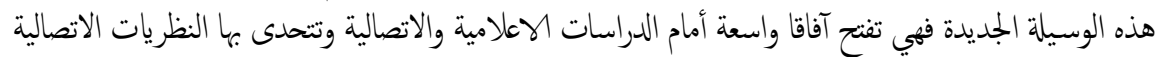
التقليدية والمفاهيم التقليدية لعملية الاتصال وأطرافها.

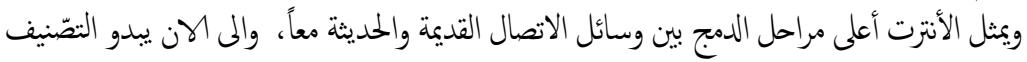

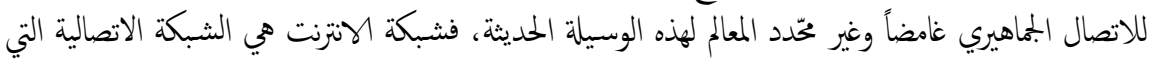

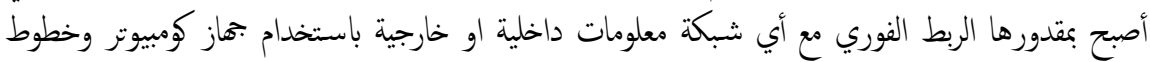
اتصالية وبذلك فهي اصبحت وسيلة اتصال وتواصل الكنرونية جهاهيرية.

ثاثلا: تحوّلات الاتصال الجماهيري في ظل التكنلوجيا الرقية الحديثة (الاترنت)

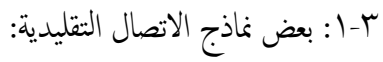

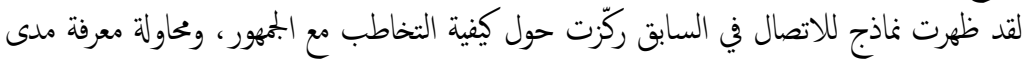

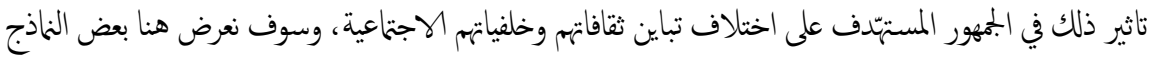

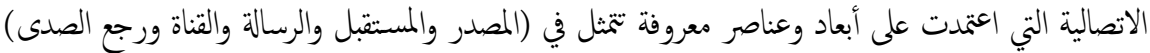

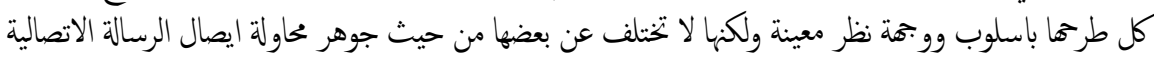

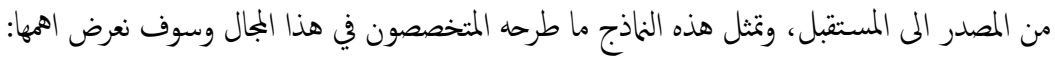

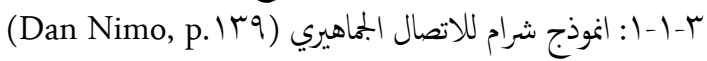

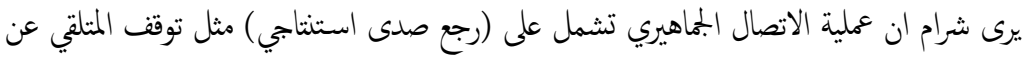

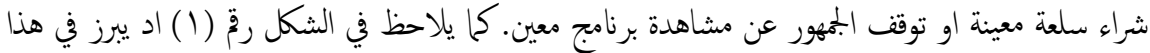

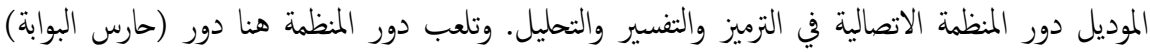

r-1-1 : انموذج مالنيزك (هادي نعان الهيتي، ص

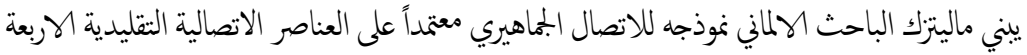

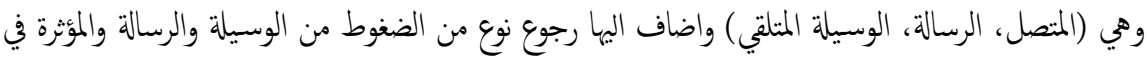

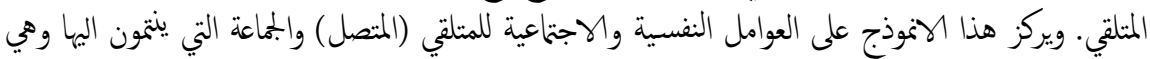

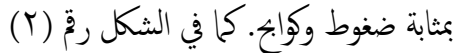

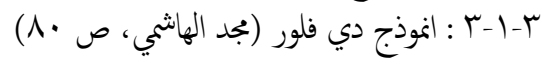

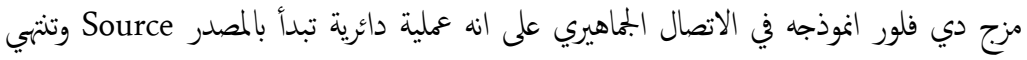

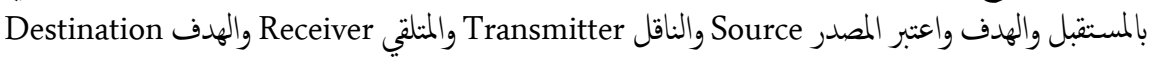
اركان منفصلة في العملية الاتصالية واعتبر التشويش منكن الحدوث في أي مرحلة من مراحل المنلي العملية الاتصالية.كما

(ب) (الشكل رقن 


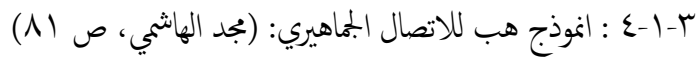

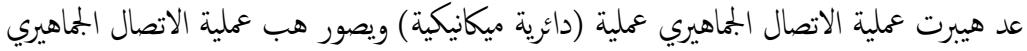

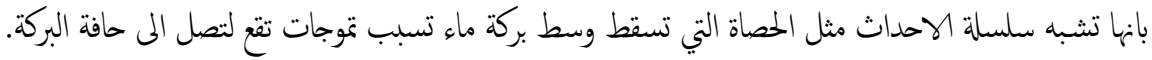

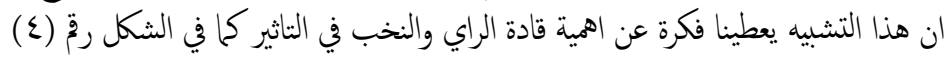

$$
\text { r-1-0: انموذج ويستلي وماكلين: (مجد الهاشمي، ص (1) }
$$

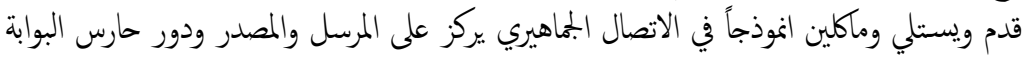

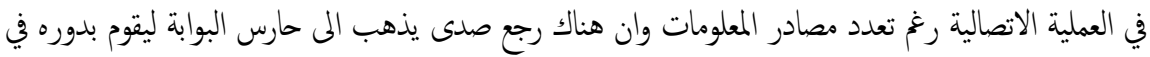

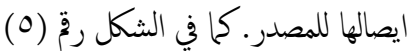

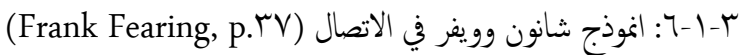

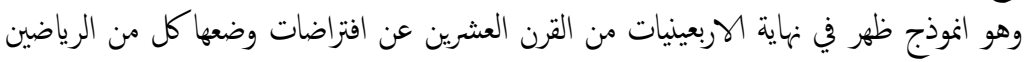

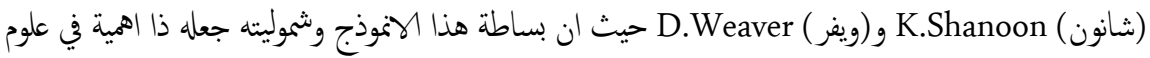
الاتصال. ويركز هذا الانموذج على خمسة عناصر اساسية وهي:

Source information

Transmitter

Channel

Receiver destination
مصدر المعلومات<smiles></smiles>

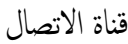

المستقبل

الوجمة

وبذلك تنتقل الرسالة الاتصالية على طول القناة بعد ان يتم تحويلها المى طاقة كهربائية ثم يعيد المستقبل بناء الاشارة. ومع شمولية هذا الانموذج اله انه لم يتضمن شروط عمل أنظمة الاتصال الميطية والمشكلات المرافقة

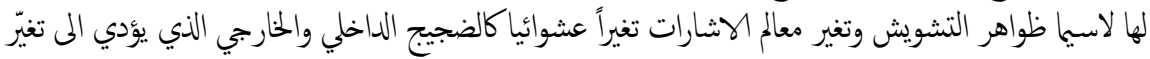

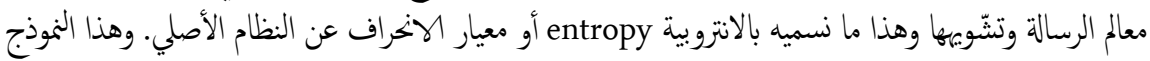

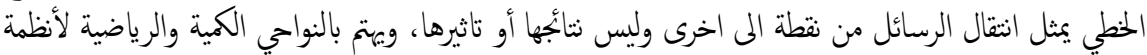

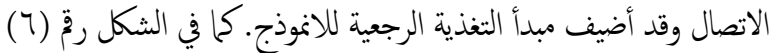

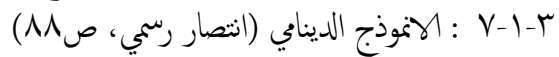

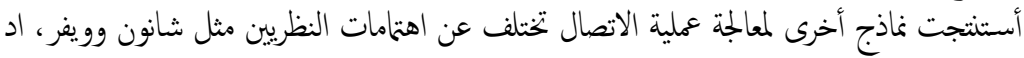

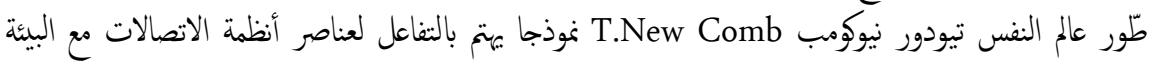

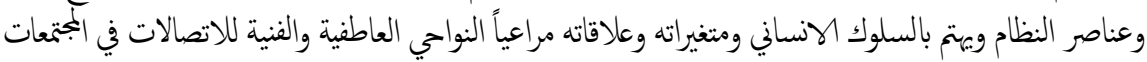

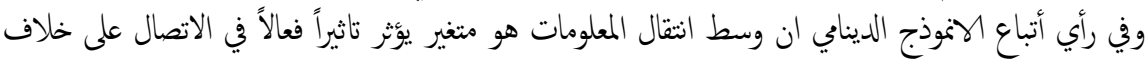




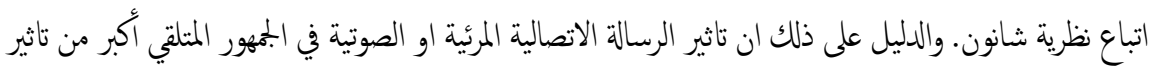

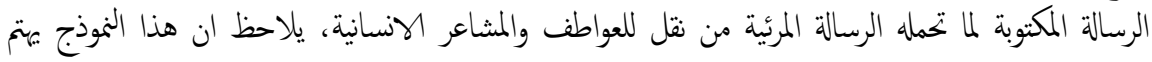

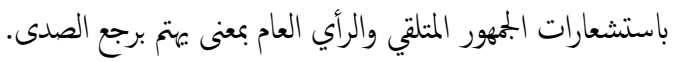
يلاحظ من هذه النظريات في الاتصال الجماهيري النظرة السلبية للجمهور ومحدودية الثفاعل بين المين

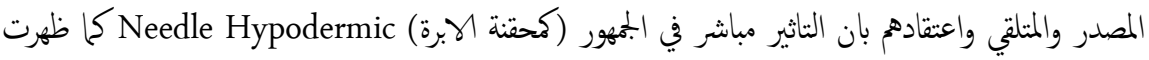

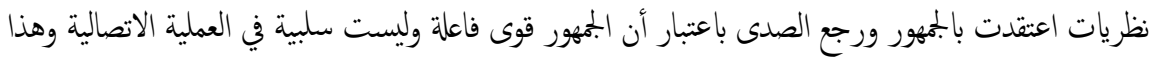

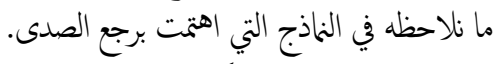

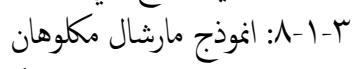
تؤمن المدرسة الامريكية بالنجج العلي القائم على التياس الكي والتجريب العملي وهناك التجاه الماردارس

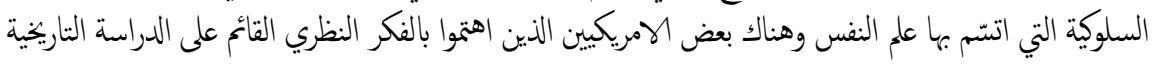

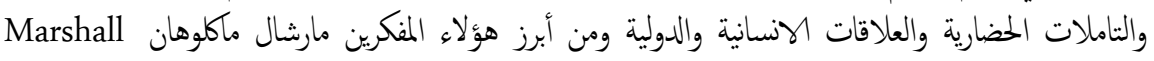

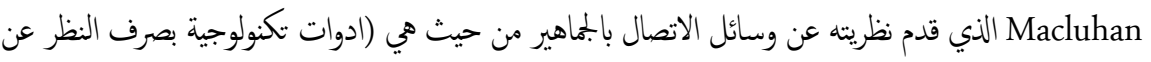

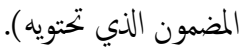

وملخص هذه النظرية ان الناس يثأثرون تأثرا لا شعوريا" بوسائل الاتصال، ولا يلبث أن يصبح هذا

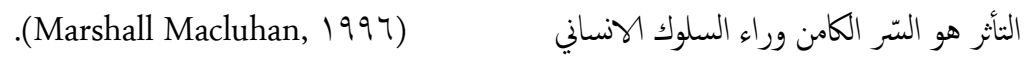

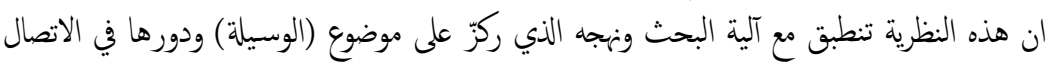

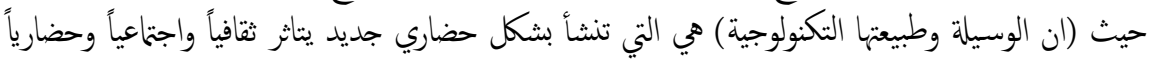
وانسانيًا بهذه الوسيلة التكنولوجية المستخدمة.

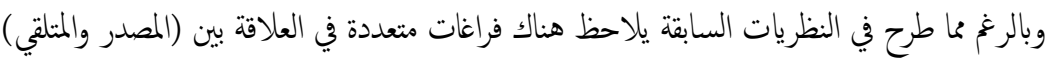

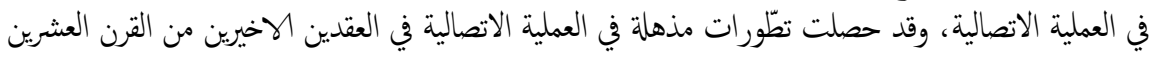

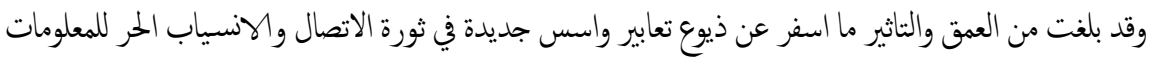

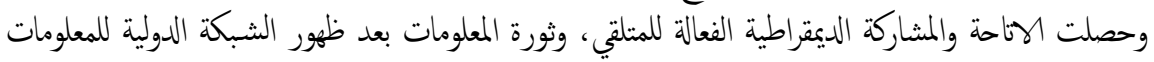

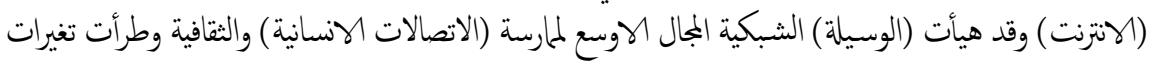

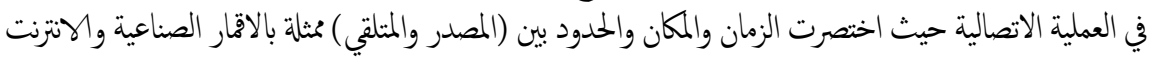

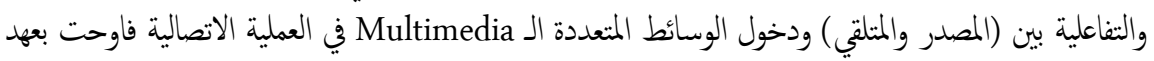

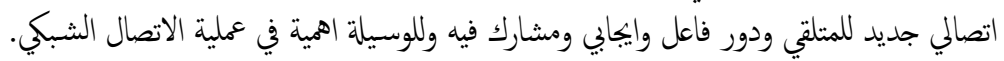

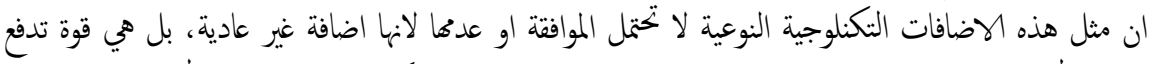

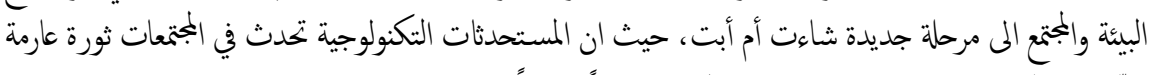

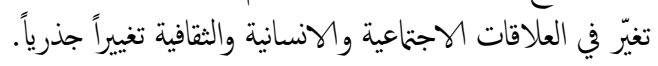

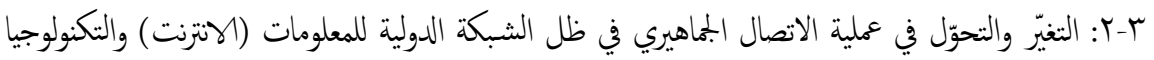
الحديثة 
عد Meerrill morris and organ في دراستها عن مفهوم الانتزنت كوسيلة اتصال "ان الانترنت وسيلة اتصال جاهيري متعدّد medium multifaceted mass فهي تحتوي على الاتصال الشخصي والاتصال

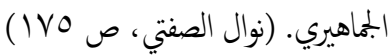
وقد توصل الى النتيجة نفسها كثير من الباحثين الذين رأوا ان (الاتصال عبر الانتزنت) يحقق ثلاثة

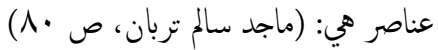

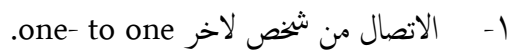

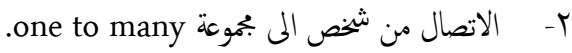

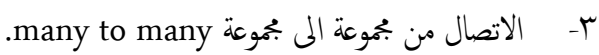
وقد أسهم الانترنت والتكنلوجيا الحديثة في تغيّر مفهوم عملية الاتصال عن ذي قبل وأصبحت هناك

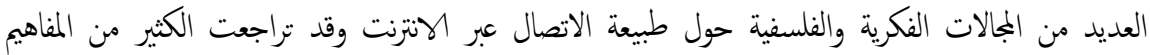

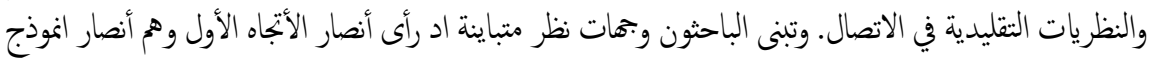
الاتصال Communication Transportation and Transmission (CTM النين يركزون على عملية انتقال المعلومات القائمة في جوهرها على عمليتين Transportation and Transmission، بينما يرى أصحاب الاتجاه الثاني وهم أنصار نموذج الاتصال الثقافي communication cultural الذي يقوم على ارسال الرسالة عبر

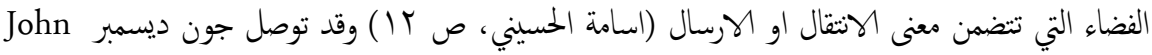

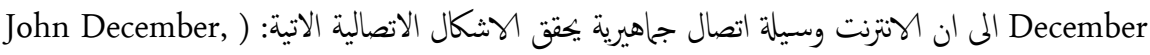
$:(\mathrm{p}) \varepsilon$

1- اتصال متزامن Synchronas communication: ويكون من فرد المى اخر او اخرين، ويكون

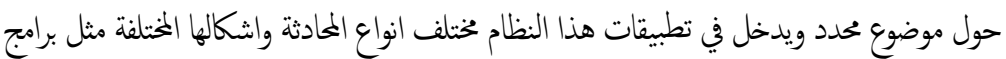

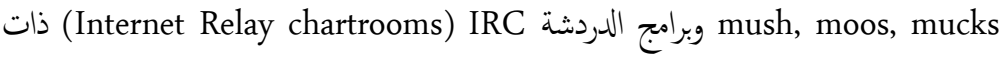
الخدمات التجارية.

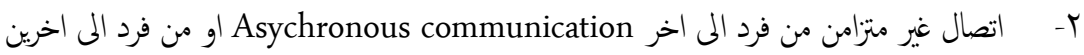

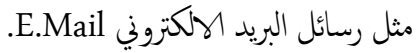

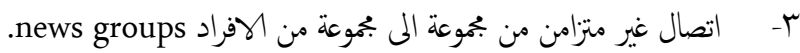

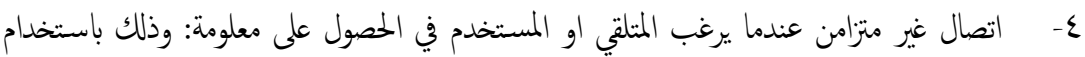

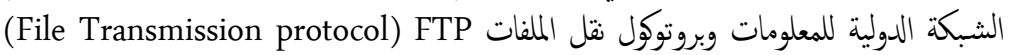

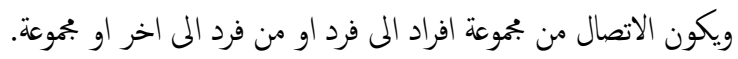
وهناك وظائف اتصالية اخرى للأنترنت في ظل التطورات التكنلوجية الحديثة تتمثل في تقديم الخدمات المباشرة للجمهور المستقبل وتحقيق الأرباح للشركات والمعلنين عن السلع والخدمات، وتمثل هذه الوظائف

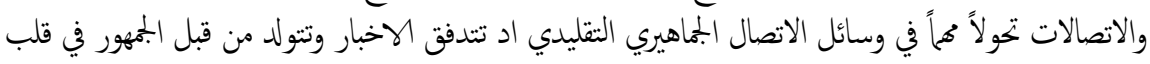
الاحداث او ممن لمم اهتمامات ملحة في نشر الاحداث الصاثل وليس فقط من قبل الصحفيين المهنيين. 
فبفضل الشبكة الدولية للمعلومات يكن لأي فرد أن يصبح صحياً او ناشراً او قائما" بالاتصال كما

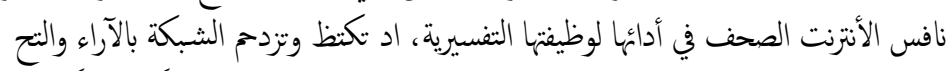

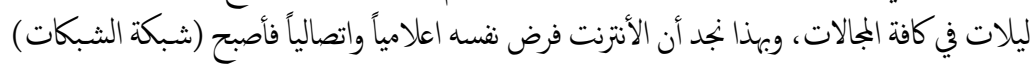

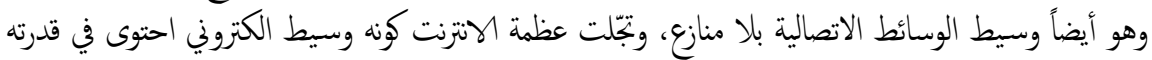

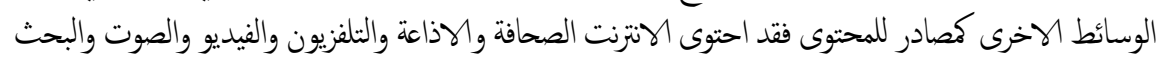

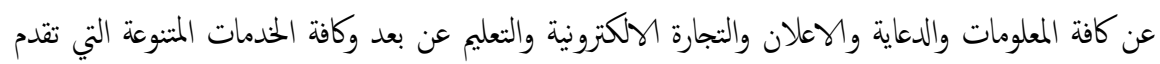
اللجمهور المستقبل اتصالات وبريد الكتروني وغيرها كثير. من خلال الكومبيوتز والشبكة الدولية مكن الثفاعل مع المواد التلفزيونية وتوفير مرونة أكبر في انتقاء

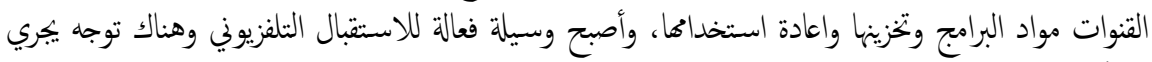

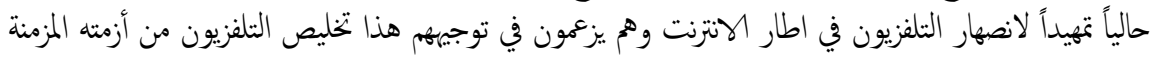

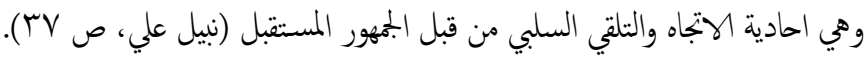

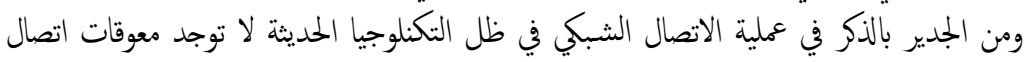

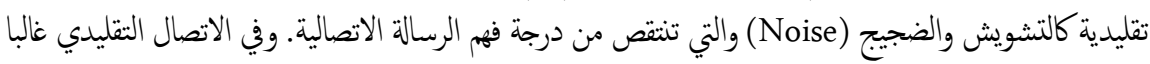

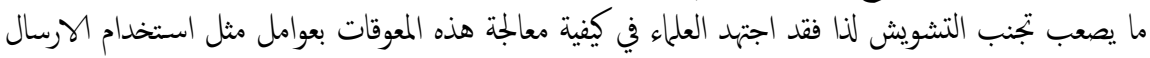

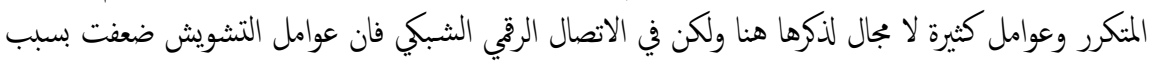

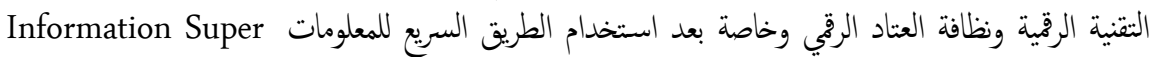

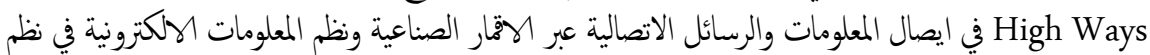
متداخلة ومتطوّرة.

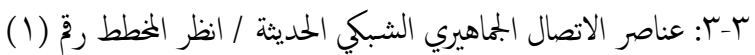

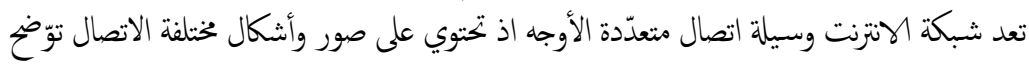

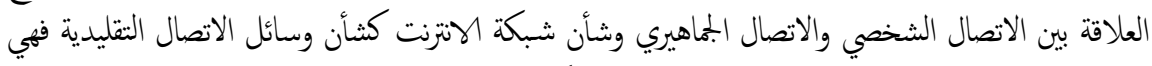

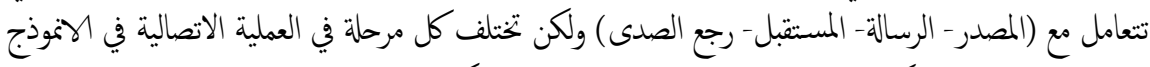

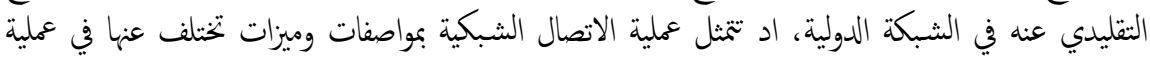

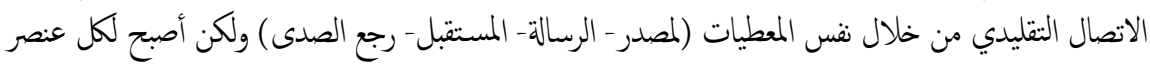

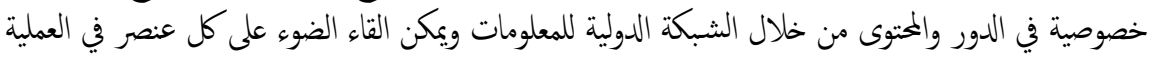
الاتصالية (الشبكية) الحديثة وفقا للآتي:

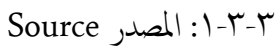

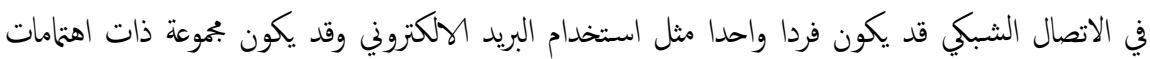

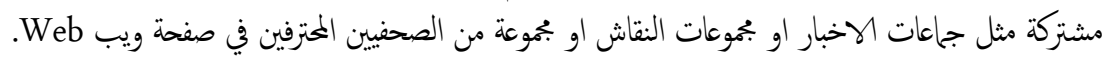
:Massage 
تختلف أشكال الرسائل في الاتصال الشبكي عنه في الاتصال التقليدي فتتخذ اشكلا متنوعة، فقد

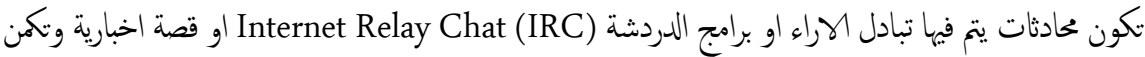

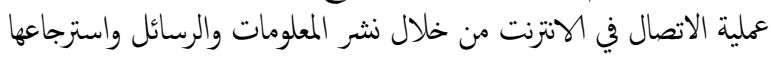

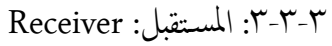
وهو المجهور المستقبل للرسائل الشبكية فقد يكون فرداً او عدة ملايين، كما يتيح الانترنت فرصاً

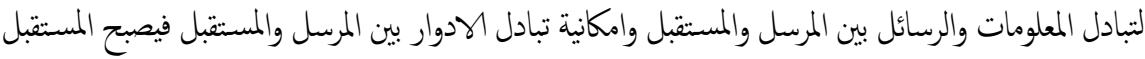

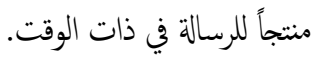

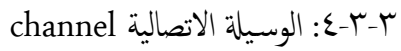
لقد تحوّلت عملية الاتصال فأصبح التزكيز على (الوسيلة) او ما تسمى بالقناة الاتصالية في عملية التراسل

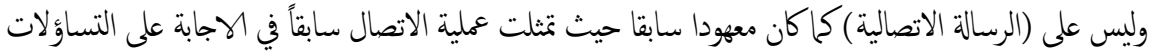

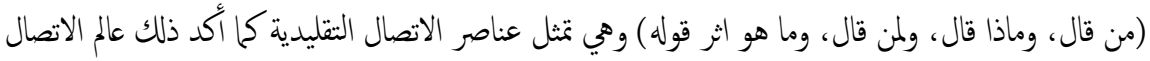

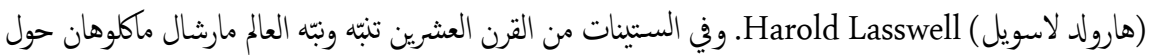

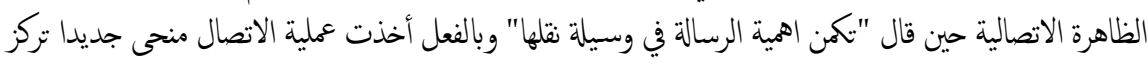

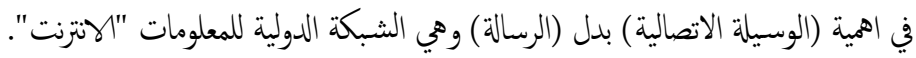

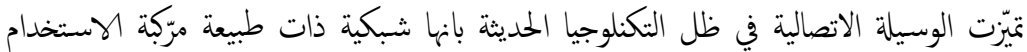

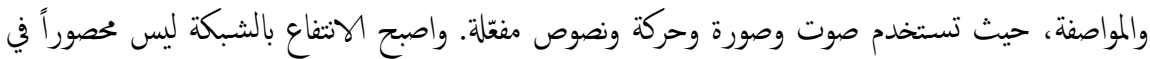

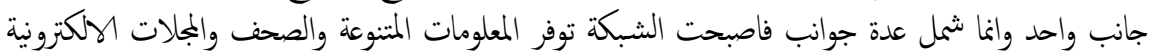

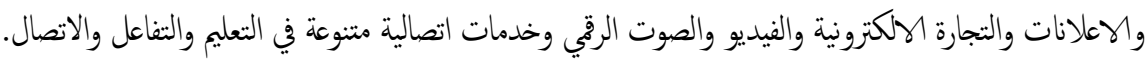

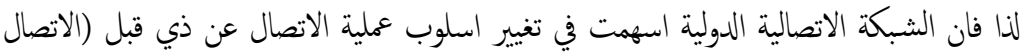

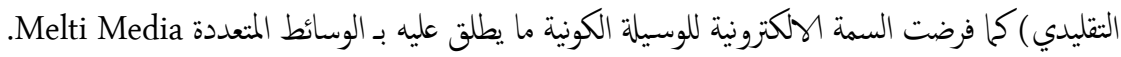

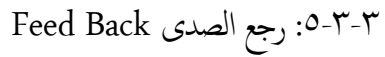
لم يعّد رجع الصدى تقليدياً كما في الاساليب الاتصالية التقليدية بل اصبح تفاعلياً ويستخدم الاتصال

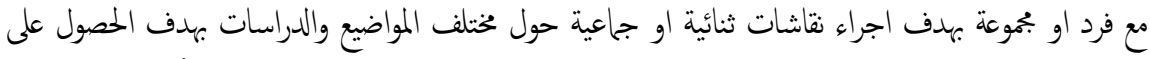

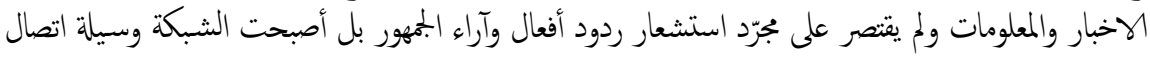

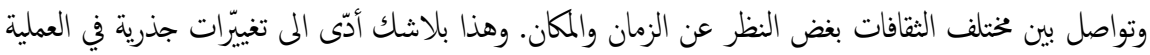

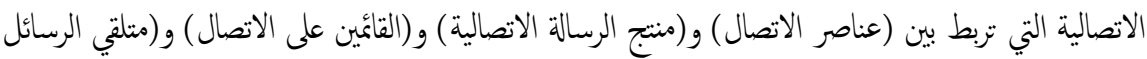

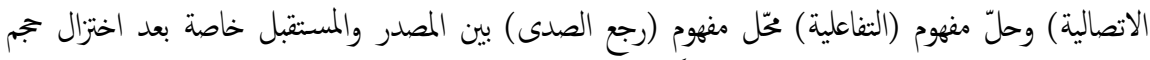

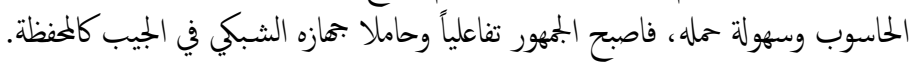

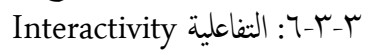

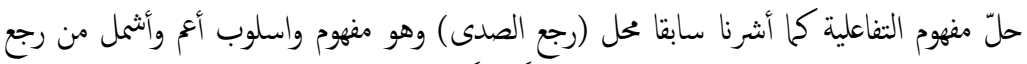

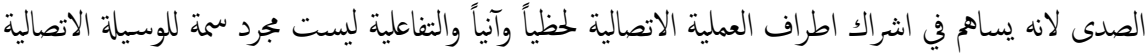




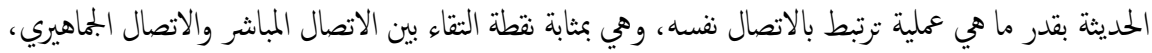

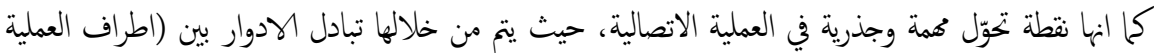

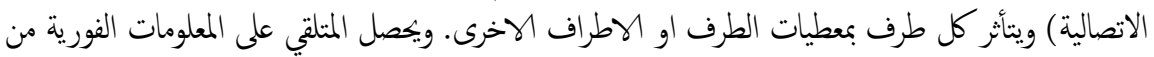

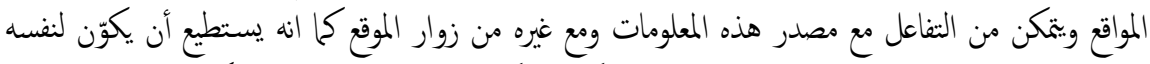

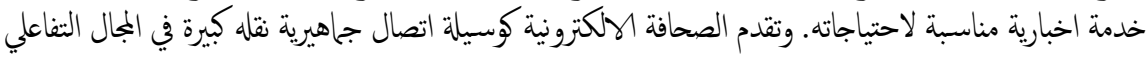

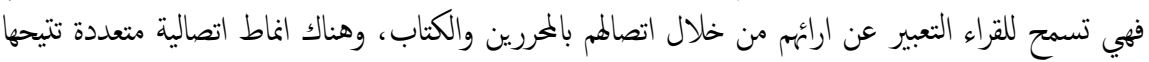

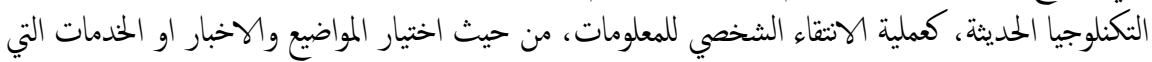

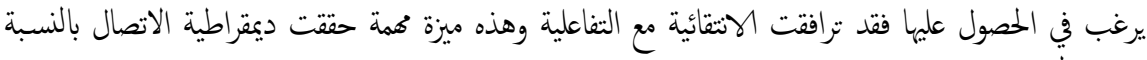
الفرد والمجتمع.

ويلاحظ من الخخطط رق (1) تبادل الأدوار والتفاعلية بين مصدر الرسالة أو المرسل وبين المنتلي فرد

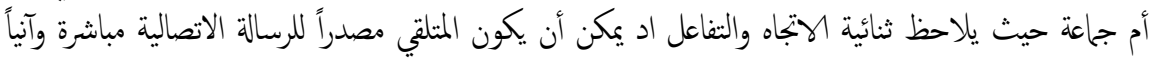

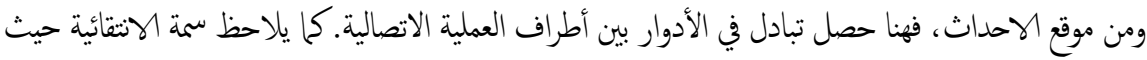

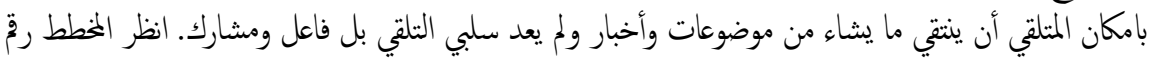

( V-r-r

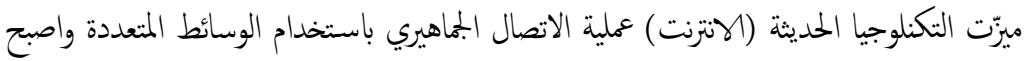

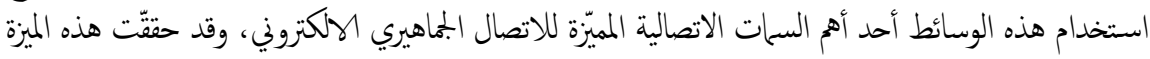

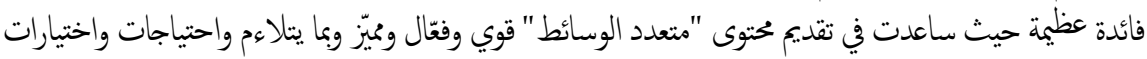

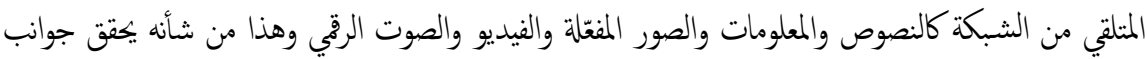

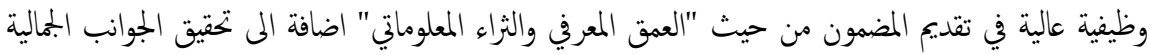

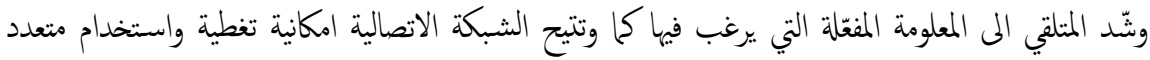

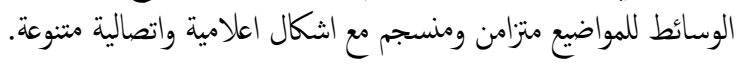

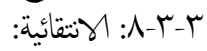

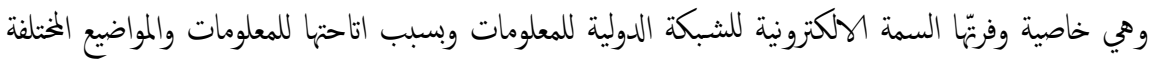

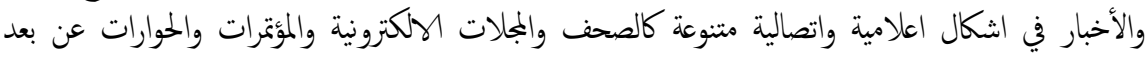

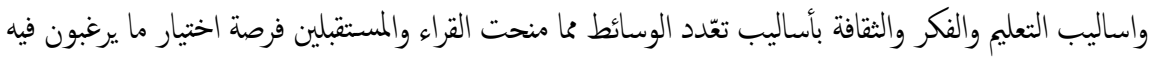

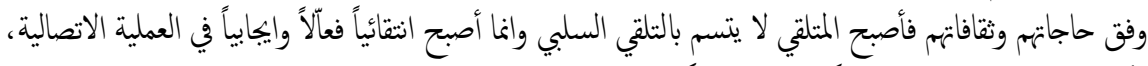

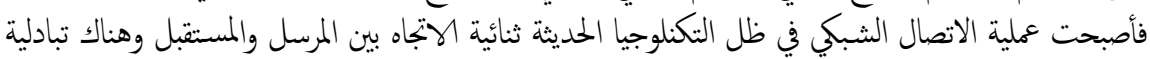

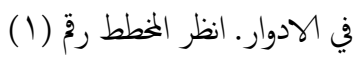
ب-ع:تقديم نموذج المخطط الاتصالي الشبكي الإنساني 


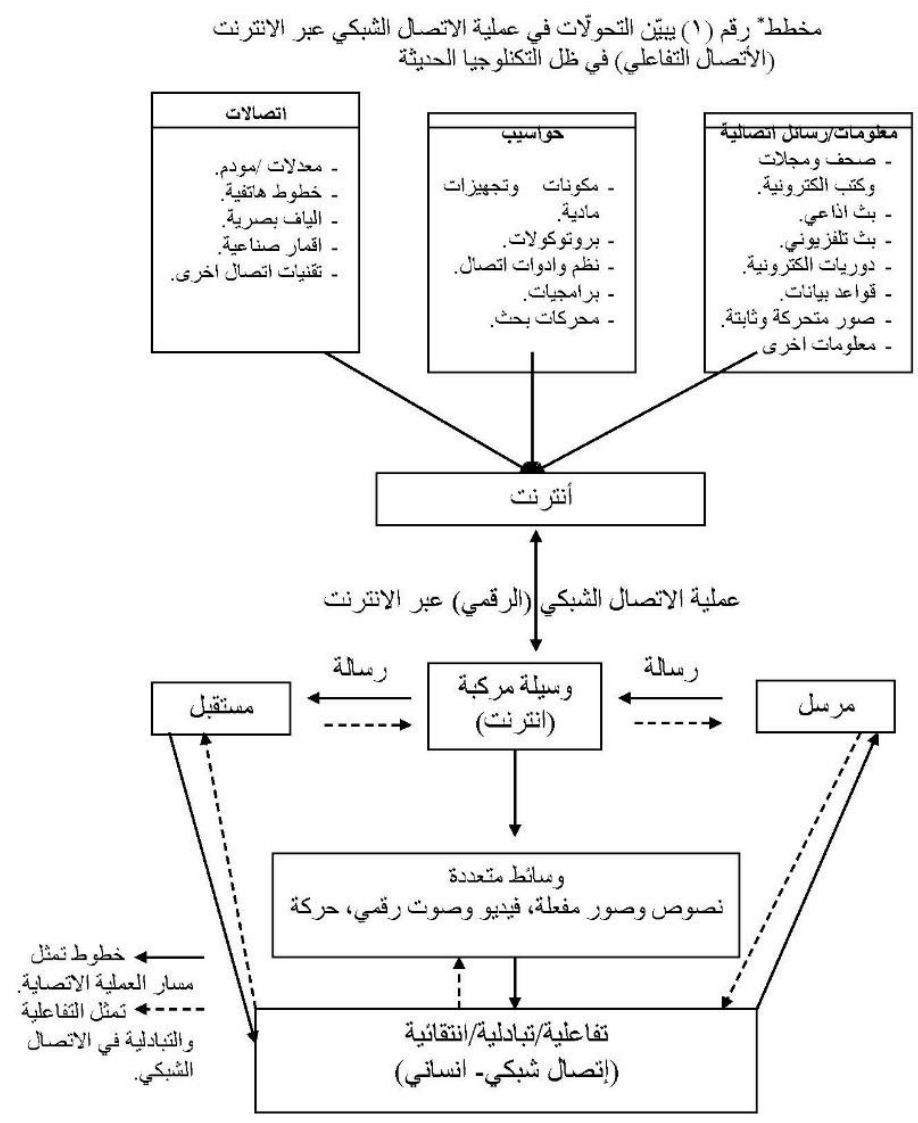

Humanity communication Net (HCN) مخطط الباحثة من خلان ما توصن اليه البحث. نموذج * 
رابعا": بعض أنواع الاتصالات التفاعلية عبر الانتزنت وتتم الثفاعلية في هذا الوسط الاتصالي الجماهيري (الأنترنت) باسلوبين: ع-1: الاتصال الثفاعلي المباشر: وهو النمط الذي تتحقق فيه التفاعلية بشكل مباثر ويتم عبر مشاركة القزّاء في غرف الحوار

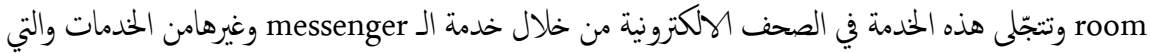

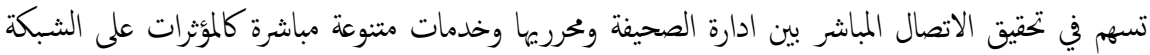

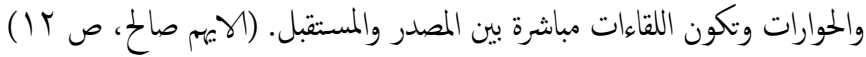
ع-r: الاتصال النفاعلي غير المباشر:

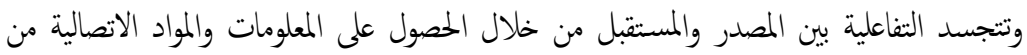

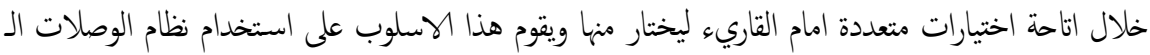

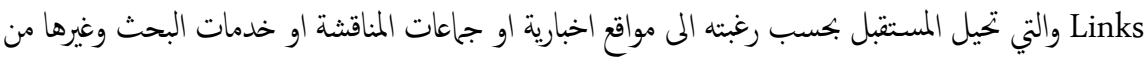

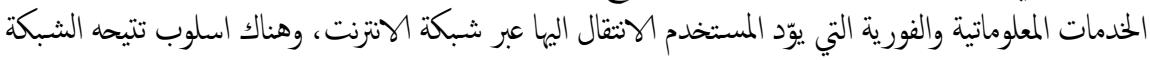

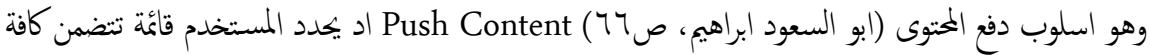

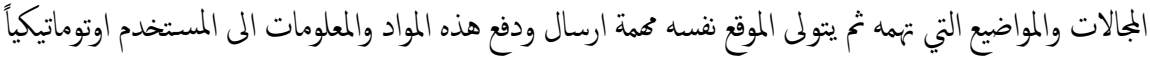

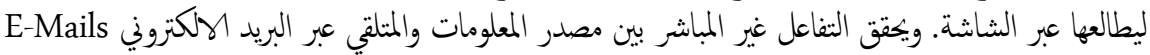

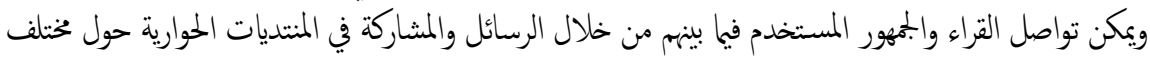

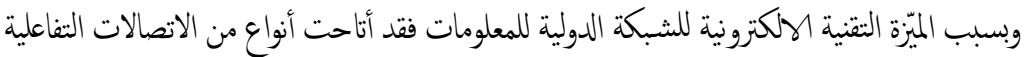

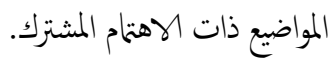

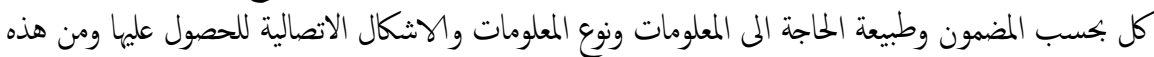

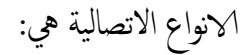

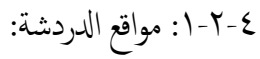

ظهرت هذه الخدمة بعد تزايد تيار جديد وحاجة جاهيرية وهو اتاحة مساحة واسعة امام مستخدي

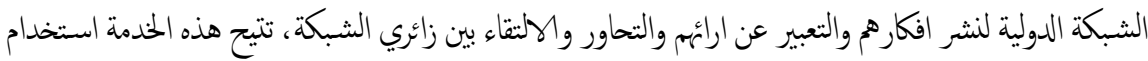

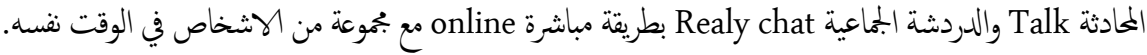

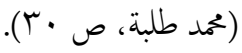

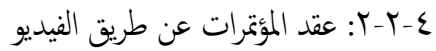

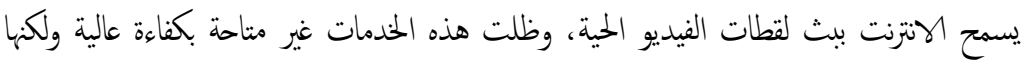

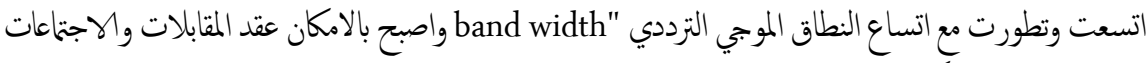

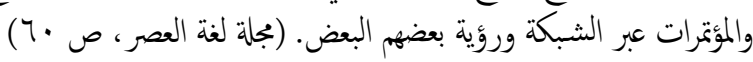




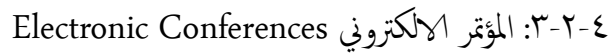
وهو الصورة الالكترونية لعقد مؤتمر او ما يسمى "حواراً تفاعلياً" باستخدام الهاتف ويككن ان يمثند

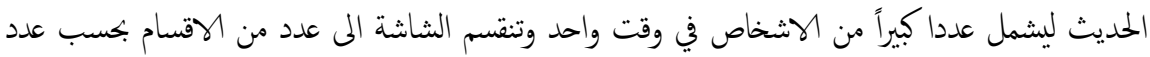

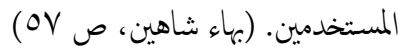

$$
\begin{aligned}
& \text { ع-r-乏: نوادي الشبكات }
\end{aligned}
$$

تختص نوادي الشبكات بموضوعات معينة مثل الفنون والسياحة والتعليم والاخبار وغيرها ويستطيع

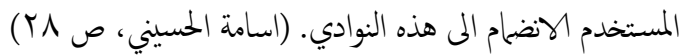

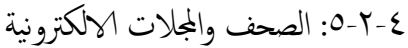

يضم الاتنزن الصحف والمجلات الكلكترونية بعضها متخصص والبعض الاخر عام ويكتوي بعضها

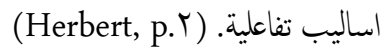

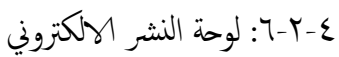

وتمثل خدمة لوحة النشر الاككتروني Bulletin Board System مستودعاً للملفات والرسائل وغالبا.

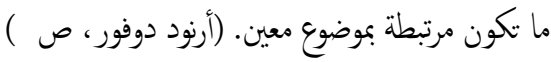

$$
\begin{aligned}
& \text { ع- V-Y البحث عن المصادر }
\end{aligned}
$$

يجري البحث عن المصادر والملفات في الشبكة عن طريق بروتوكول نقل النصوص باستخدام ادوات

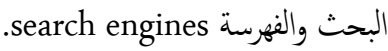

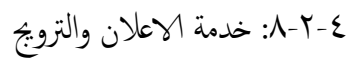

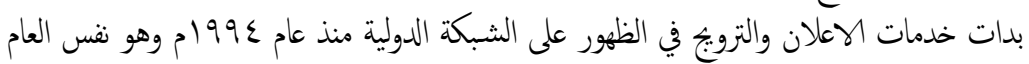

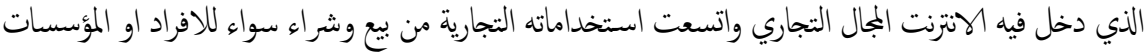

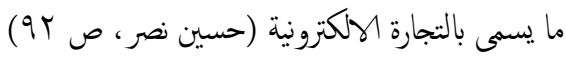

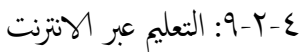

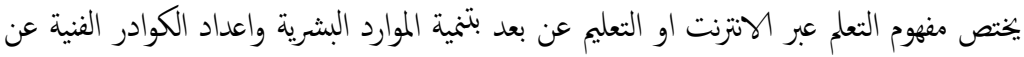

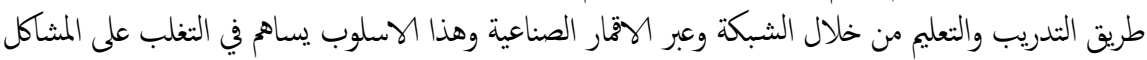

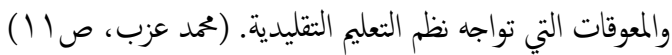

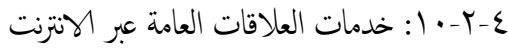

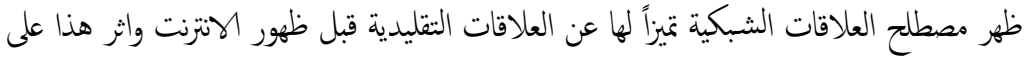

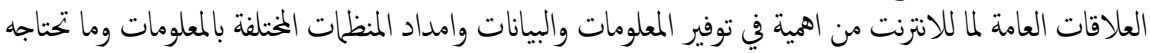

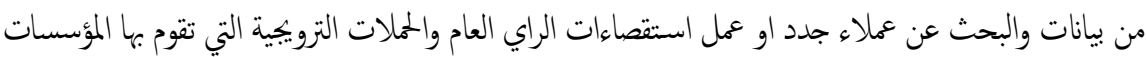

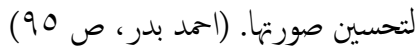

$$
\begin{aligned}
& \text { خامسا: نتائج البحث : لتحسن }
\end{aligned}
$$


تلخصت نتائُ البحث بتشخيص طبيعة عناصر الاتصال الجماهيري باستخدام التقنيات الالكترونية

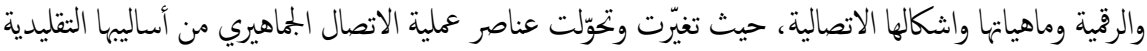

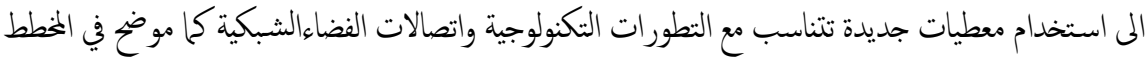

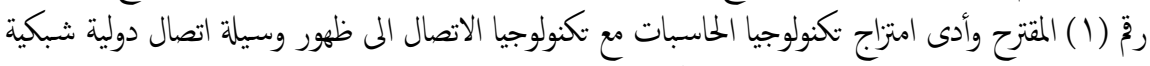

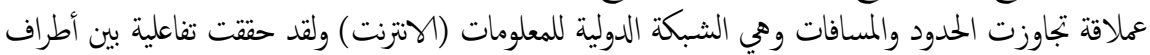

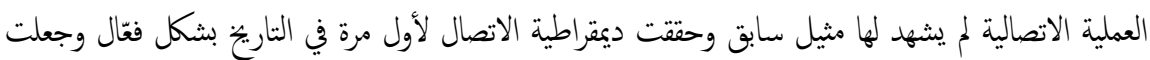

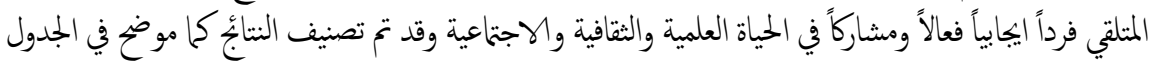

ر)

جدول رقٌ (1) يوضح نتائُ البحث

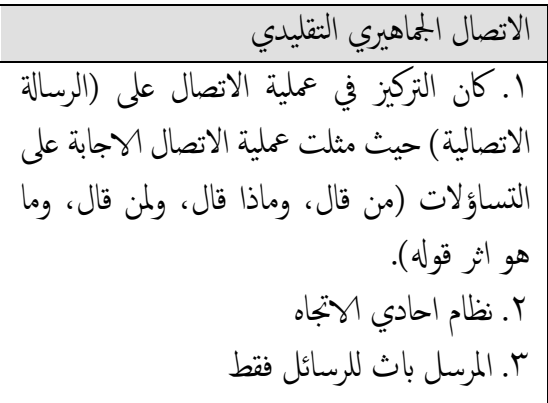

ع المتلقي سلبي في أغلب الاحيان 0.الوسيلة الاتصالية الحادية الاستخدام وتحوي الميلتي

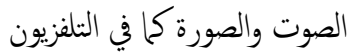

7. V V. تنقل الرسائل الاتصالية بواسطة الموجات الصوتية والكهرومغناطيسية. A. الرسائل الاتصالية غير انتقائية فهي مفروضة على الجمهور المتلقي.

9.محدودية معرفة عملية رجع الصدى واستشعار

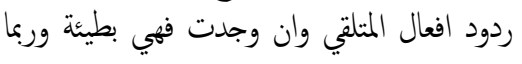

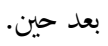

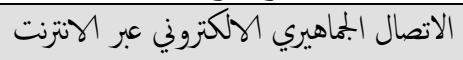

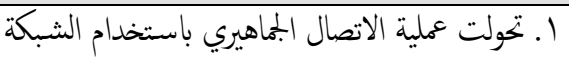
الدولية للمعلومات فقد اصبح التزكيز على (الوسيلة) وهي (الانترنت) في عملية الاتصال ونقل الرسائل الريل الاتصالية بدل الرسالة. r. - نظام ذو اتجاهين r. المرسل فعّال ويكن ان يكون مرسل ومستقبل في

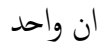
ع. المنتلي ايجابي ومشارك ومتفاعل.

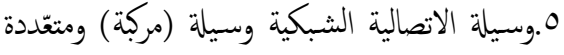

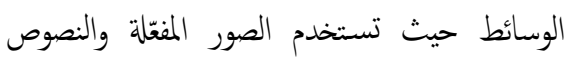

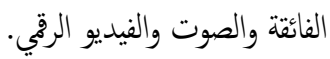
7.

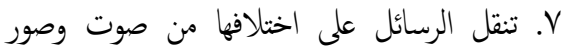
ونصوص بهيئة رقية تعتمد نظام الـ (1 , • • ) في تمثيلها.

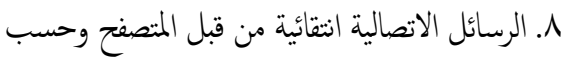
رغبته وهي متاحة لجماهير واسعة وعريضة في الكرة

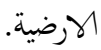
9. اطلاع واسع وآني على ردود افعلّل القراّه والمتلقي مشارك وفعال في عملية الاتصال الشبكي. 


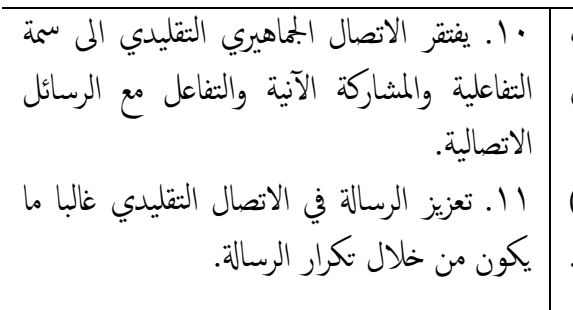

بالي أ الاشارات التي تنقل الرسائل الاتصالية عبر

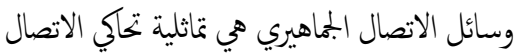
كما في الهاتف واشارات الراديو والتلفزيون.

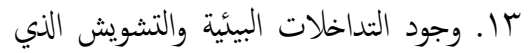
يؤثر على الرسالة. ع ا. محدودية في الاتصال التقليدي ويتمند على التحان

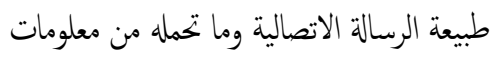

17 ا تعمل نظم الاتصال الجماهيري التقليدية منفردة عن بعضها وعن نظم المعلومات والحاسبات.

C ا ا محدودية الثاثير في الاتصال التقليدي ومحدودية c المشاركة الفعالة.

11. تكنولوجيا الاتصال منفردة وغير تفاعلية في الاتصال التقليدي.

19. تثنقد وسائل الاتصال التقليدية الى هذه السرعة.
• ا. يتميّز الاتصال الجماهيري الرقي عبر الانتزنت

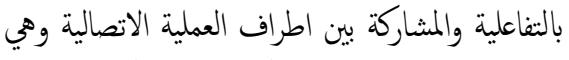
خاصية تتوافق مع السمة الاككترونية للشبكة. 11 ا الاتصال الألكتروني يحقق تعزيز (للرسالة الاتصالية)

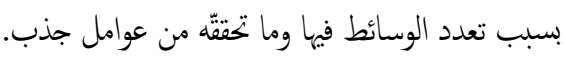
r ا. استخدام نظام رقي لتمثيل كافة المعلومات

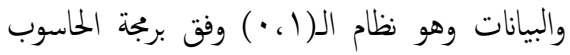
فالاشارات التي تنقل الرسائل الاتصالية هي اشارات رقيه.

با ـ البيئة الاتصالية في التكنلوجيا الحديثة نظيفة وآمنة حيث تضعف عوامل التشويش الداخلية والخارجية. ع ا. يتميز الاتصال الجماهيري عبر الشبكة بثراء معلوماتي

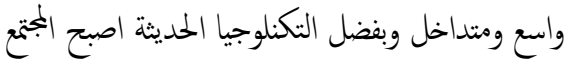

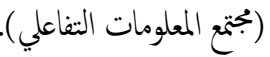
10. ادخال الوسائط المتعددة في الاتصال الشبكي

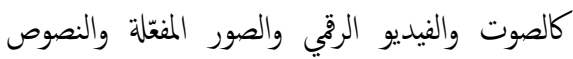
الفائقة وغيرها ما ساهم في تحقيق أبعاد وظيفية وجالية ولية المعتية في الرسالة الاتصالية. - مغالئ

17 ـ أرتبطت نظم الاتصال في التكنلوجيا الحديثة بنظم الحاسبات وتطورت معاً ويككن ان نطلق عليه (بالاتصال

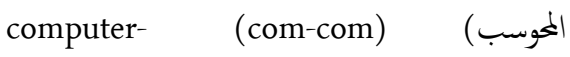
. communication IV . وسائل الاتصال الشبكية الحديثة ذات تاثير واسع

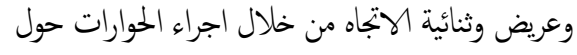
العالم (وبلا حدود). 1 ا ـ تولّدت تكنولوجيا مركبة ناتجة من مزج تكنولوجيا

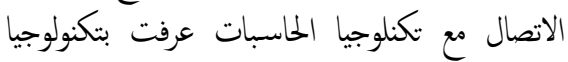
الاتصال الثفاعلي interactive communication 


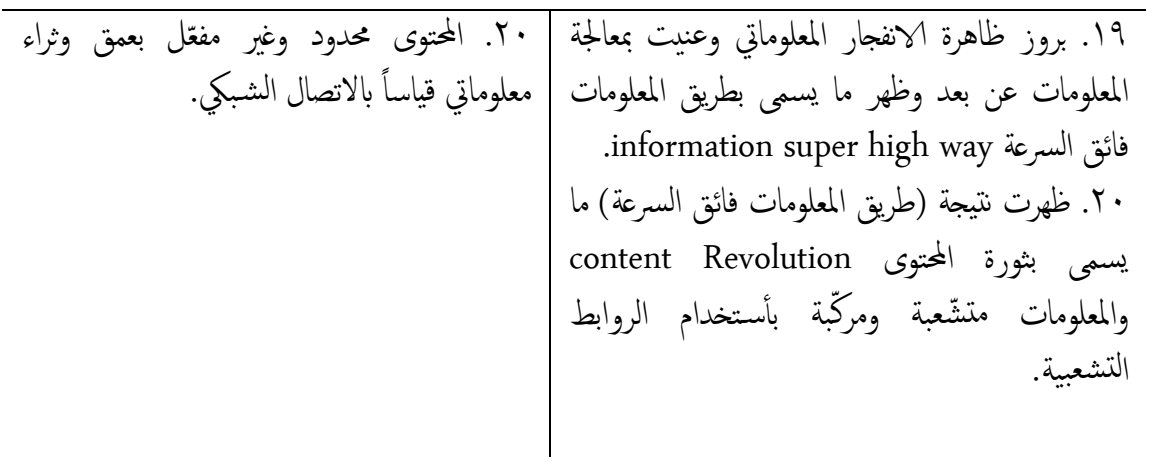

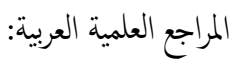

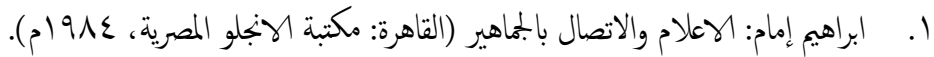

r. ابو السعود ابراهيم ومحد عبد الهادي: النشر الكلكتروني ومصادر المعلومات الهلكترونية، (القاهرة:

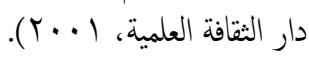

ب. احمد بدر: الاعلام الدولي، دراسات في الاتصال والدعاية الدولية، طع، (القاهرة: دار قباء للطباعة

$$
\text { والنشر والتوزيع). }
$$

ع. ارنود دوفور (متزجم): زدني علماً انتزن، ترجة: منى مليحس ، (بيروت: الدار العربية للعلوم،

. (1991

0. اسامة الحسيني: الشبكة الكومبيوترية العالمية انترنت، القاهرة: مكتبة ابن سيناء، 1997.

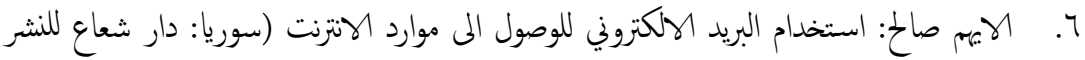

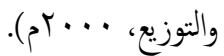

$$
\text { V. . . مهاء شاهين: شبكة الانتزنت (القاهرة: كمبيوسايس لعلوم (الحاسب)، } 1999 \text { (م) ). }
$$

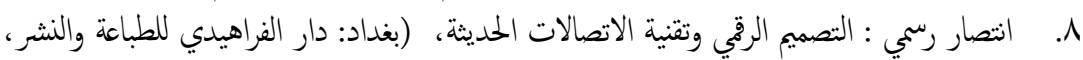

$$
\text { (p) } 11)
$$

9.

• ا. ههد العسكر: التقنيات الصحفية الحديثة واثرها على الاداء المهني للصحف المعاصرة، (الرياض: دار

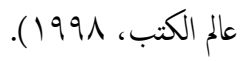

ا ا. ماجد سالم تربان: الانتزنت والصحافة الكلكترونية، رؤية مستقبلية، (القاهرة: الدار المصرية اللبنانية،

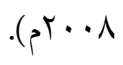

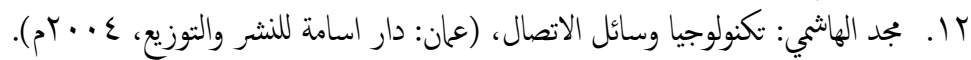

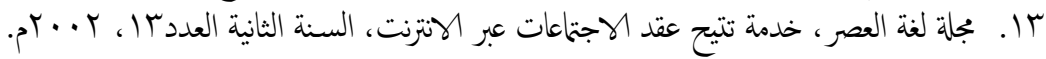

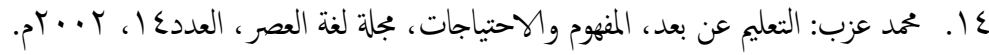




$$
\text { 10. محمد طلبة، الانتزنت، طا ، (القاهرة: مطابع المكتب المصري الحديث، 1997 19 ). }
$$

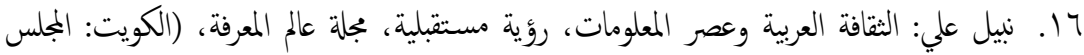

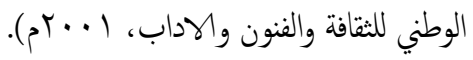

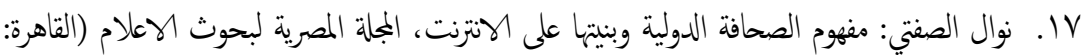

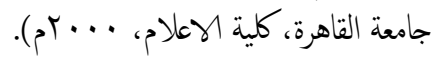

11. هادي نعان الهيتي: الاتصال الجماهيري، المنظور الجديد، دار الشؤون الثقافية، (بغداد: 1991م).

$$
\text { المصادر العلمية الاجنية: }
$$

19. Dan Nimo: Political communication and public opinion in Amarical sata Monico, California: Goddyear publishing company, 19V^. $\uparrow \cdot$. Frank Fearing: Human communication in Dexter white people society \& mass communication, $197 \%$.

r. Herbert, J, Jour nalism in the dgitd age, Boston: focal press, ${ }^{\prime} \cdots$. rr. Hibert Ungurait \& Bhn, Mass Media New York: Longman, $19 \vee 9$.

Y . John December: Uses of Analysis for internet, "communication Journal", vol. ¿7, no. I.

Y०. marshall McLuhan, understand Media-The Extension of man , New York,

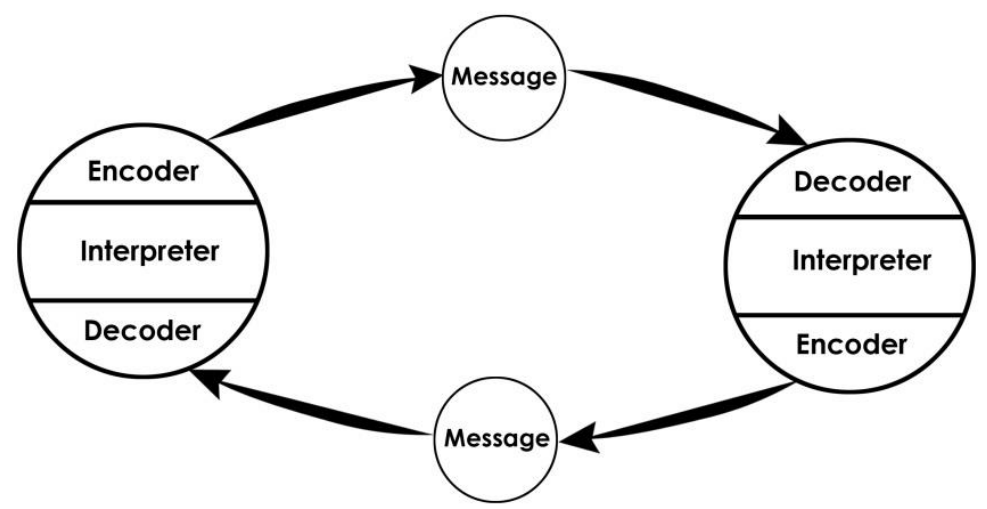

$$
\text { شكل رق (1) بمثل موديل شرام للاتصال الجماهيري }
$$




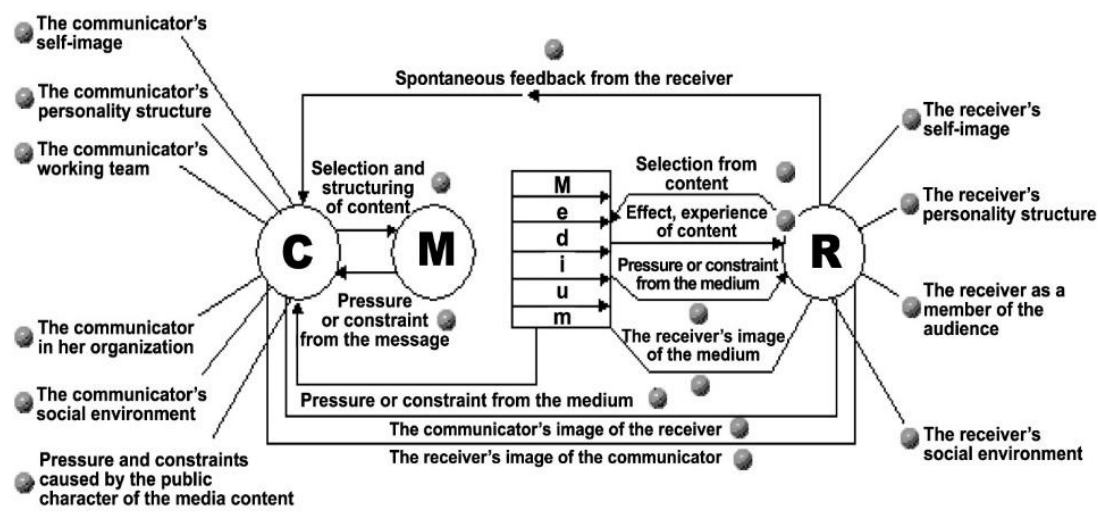

شكل رقز (Y) ميثل نموذج مالتيزك

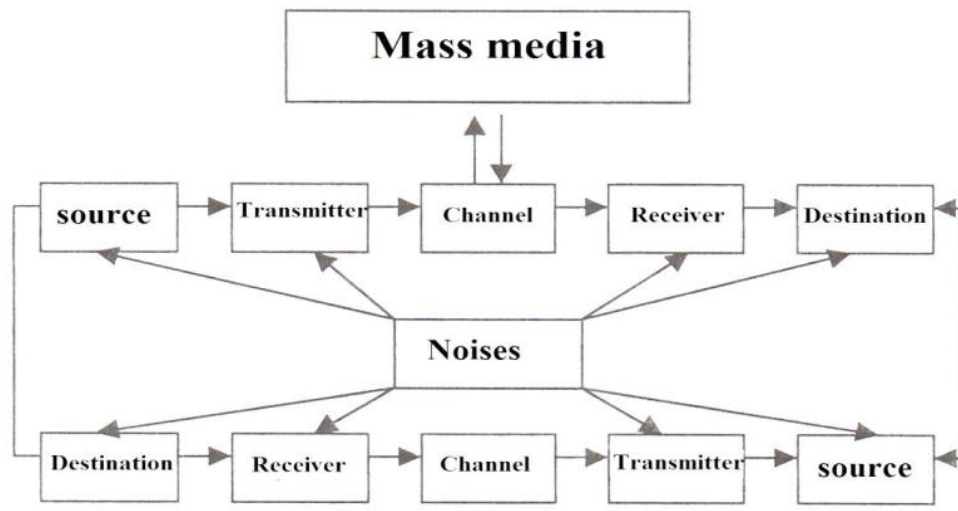

شكل رقة (r) يمثل نموذج دي فلور 


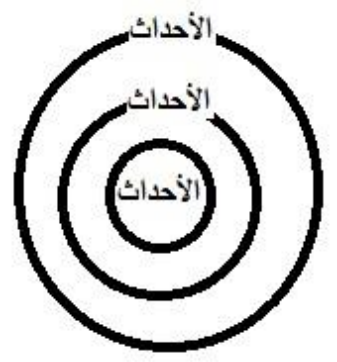

شكل رقز (ع) يمثل نموذج هب للاتصال الماهيري

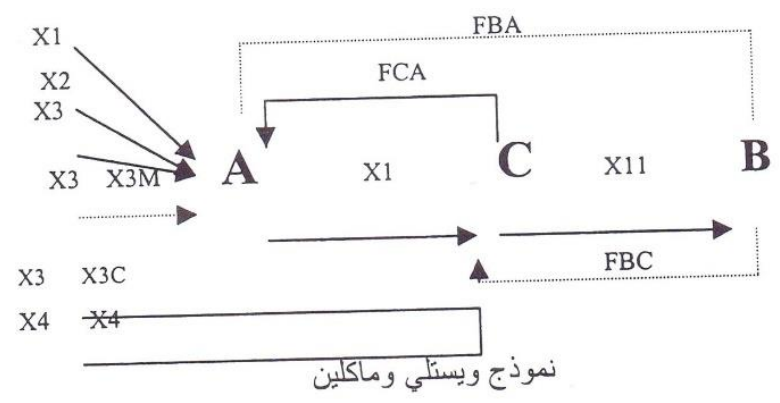

شكل رقز (0) يمثل نموذج ويستلي وماكلين

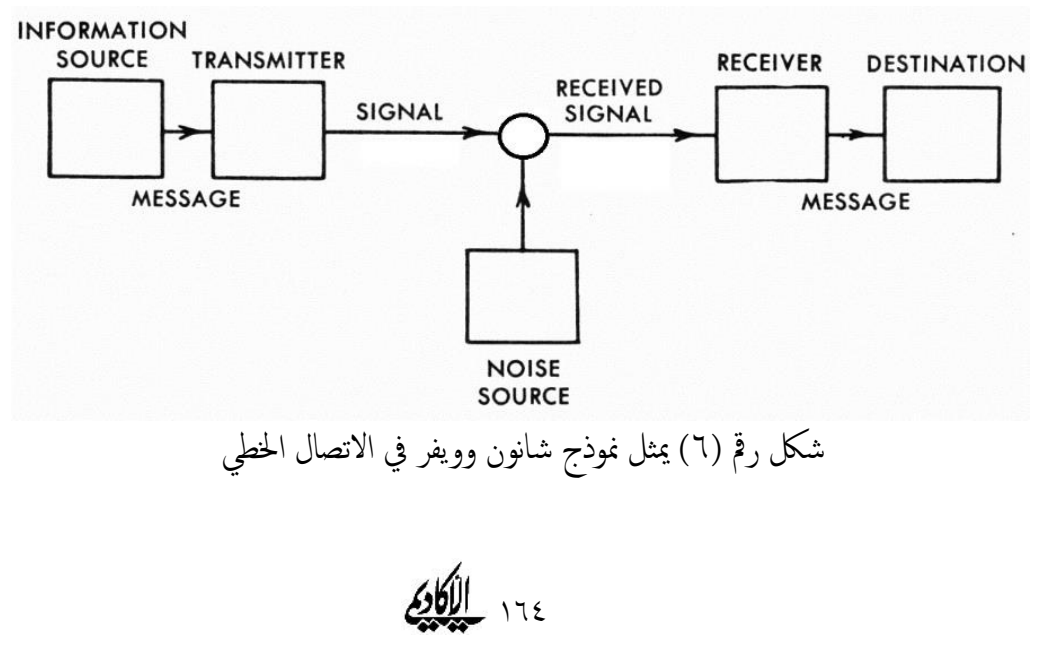

